Article

\title{
Watchdogs, Advocates and Adversaries: Journalists' Relational Role Conceptions in Asylum Reporting
}

\author{
Markus Ojala ${ }^{1, *}$ and Reeta Pöyhtäri ${ }^{2}$ \\ ${ }^{1}$ Department of Social Research, University of Helsinki, 00014 Helsinki, Finland; E-Mail: markus.ojala@helsinki.fi \\ 2 Research Centre for Journalism, Media and Communication COMET, University of Tampere, 33014 Tampere, Finland; \\ E-Mail: reeta.poyhtari@uta.fi \\ * Corresponding author
}

Submitted: 24 November 2017 | Accepted: 13 April 2018 | Published: 29 June 2018

\begin{abstract}
Journalistic role conceptions are usually understood as internalised professional conventions about the tasks reporters pursue in society. This study insists that more attention be put on the relational and context-dependent nature of journalistic role conceptions. Adopting a social-interactionist approach to journalistic roles, the study examines how Finnish journalists conceived of their professional roles when covering asylum issues during the so-called "refugee crisis" of 2015-2016. Based on an analysis of open-ended, semi-structured interviews with 24 journalists, we highlight how considerations of the political context and interactions with three key reference groups-officials, asylum seekers and anti-immigrant publicsshaped the journalists' conceptions of their tasks and duties. The article contributes to the study of journalistic role conceptions by illustrating how the conceptualisation of journalistic roles in relation to reference groups takes place in practice. It also sheds light on the tensions involved in journalistic balancing and negotiation between various available role conceptions, especially in the shifting societal and political contexts of a Europe marked by multiculturalism and the simultaneous rise of anti-immigrant movements.
\end{abstract}

\section{Keywords}

asylum seekers; migration; journalism; refugee crisis; role; role conception

\section{Issue}

This article is part of the issue "Media and Communication between the Local and the Global", edited by Jessica Gustafsson (Sodertorn University, Sweden) and Kinga Polynczuk-Alenius (University of Helsinki, Finland).

(C) 2018 by the authors; licensee Cogitatio (Lisbon, Portugal). This article is licensed under a Creative Commons Attribution 4.0 International License (CC BY).

\section{Introduction}

As migration, both voluntary and forced, reshapes the lived experiences of peoples, journalism emerges as one of the key cultural practices that can facilitate the adaption of societies to increasingly global and multicultural realities. Due to their professional expertise and institutional position as the principal providers of daily knowledge about distant events, journalists are influential interpreters of global processes for national and local audiences (Berglez, 2013), while also shaping collectivelyshared social imaginaries and normative sensibilities about living in culturally diverse societies (Deuze, 2005; Ojala, 2011). However, with the recent ascendance of online counter-media platforms and "post-truth politics", news journalism has become an increasingly contested field. As challenges to the neutrality and trustworthiness of mainstream news media are being voiced by previously marginalised voices, what purposes journalism should serve and how news reporters ought to represent various political views are issues ever more frequently raised in public by those participating in contemporary societal conflicts. Having to come to terms with the diverging demands and expectations emanating from these new challengers potentially forces journalists themselves to be increasingly reflective about their professional tasks and duties. The contemporary societal environment marked by globalisation, multiculturalism 
and the simultaneous rise of anti-immigrant movements hence motivates renewed interest in the study of journalistic roles and role conceptions.

Journalistic role conceptions are cultural conventions pertaining to the occupational tasks that journalists believe they ought to perform in their social environment (Donsbach, 2008; Mellado, Hellmueller, \& Donsbach, 2017, p. 5). In journalism studies, role conceptions have traditionally been associated with certain functions that journalism is believed to (ideally) serve in society, and they have been observed to be rather constant over time in a given journalistic culture (Lewis, 2012). However, a social-interactionist perspective on journalistic roles has challenged this view by insisting that, instead of an enacted collection of internalised ideals and norms, a social role is the product of social interaction and alters from one situation to the next (Hellmueller \& Mellado, 2015). The social-interactionist approach thus emphasises the context-dependent and relational nature of journalistic roles, the meanings of which a reporter constantly negotiates through interaction with reference groups, including sources, audiences and peers.

The purpose of this article is to focus on the relational and situational aspects of journalistic roles by analysing how Finnish journalists made sense of their professional roles when reporting on a contested topic in a context of high societal tensions, namely the "refugee crisis" of 2015-2016. Along with many other countries in Europe, Finland became a destination for a significant number of asylum seekers in the latter half of 2015. Within a few months, some 32,000 migrants applied for asylum in Finland, amounting to the fourth largest number among EU member states in proportion to the overall population in 2015 (Eurostat, 2016). Given the fact that approximately 40,000 asylum seekers in total had arrived in Finland in the previous four decades, the new situation became an intense political and societal issue, prompting both citizen activism in solidarity with asylum seekers and anti-immigrant demonstrations and violence. Indeed, dubbed a "refugee crisis" by the news media and political commentators, the Finnish debate in many ways echoed discourses elsewhere in Europe that focused on the perceived risks of migration (e.g., Greussing \& Boomgaarden, 2017; Harrison, 2016; see also Vertovec \& Wessendorf, 2010), but also featured powerful expressions of solidarity and condemnations of xenophobia (Holmes \& Castañeda, 2016). Significantly for our purposes, the refugee debate involved critical questions about the role of the news media in these developments. Far from enjoying a hallowed position as a trustworthy informer about international and local events or as a neutral mediator between conflicting viewpoints, news workers were regularly accused of questionable reporting that distorted reality in favour of certain ideological ends. Journalism hence became a highly politicised cultural practice in the societal struggles over immigration, multiculturalism, tolerance, human rights and racism.
This study examines how Finnish journalists conceived of their professional roles when covering the "refugee crisis". More specifically, by adopting the socialinteractionist approach to journalistic roles, we analyse how considerations of the political context and interactions with three key reference groups-officials, asylum seekers and anti-immigrant publics-shaped journalists' perceptions of their professional tasks and duties. The study thus contributes to social-interactionist theorisation about journalistic role conceptions by illustrating how reporters' conceptualisation of their professional roles in relation to reference groups takes place in practice. We highlight not only that journalists' role conceptions vary according to the specific reference group they interact with, or have in mind when writing a story, but also that their attitudes towards particular reference groups, and hence their role conceptions, depend on the way they perceive the broader societal context, which tends to shift over time. In sum, the study both corroborates and substantiates social-interactionist theorisation of journalistic roles.

\section{Journalistic Roles and Role Conceptions}

There is a rich tradition of research concerning the roles journalists perform in society. Theoretical and normative lines of inquiry (e.g., Christians, Glasser, McQuail, Nordenstreng, \& White, 2009; Siebert, Peterson, \& Schramm, 1956) have been complemented by empirical observations of journalistic work (e.g., Gans, 1979; Tuchman, 1978) as well as by interviews and surveys focusing on journalists' own conceptions of their roles (e.g., Hanitzsch et al., 2011; Weaver \& Willnat, 2012). In this body of literature, journalistic roles are typically understood as the tasks and duties served by journalism, or those that it ought to serve, in society. As such, they are informed by "expectations, values, norms and standards defining how news people and organizations should and do work" (Hellmueller \& Mellado, 2015, p. 4). As these tasks and duties are internalised during professional training and work, journalists develop corresponding personal and collective role conceptions, or beliefs about the expectations of others, which guide their actions on the job (Donsbach, 2008; Hanitzsch \& Vos, 2018). Accordingly, journalistic role conceptions have been identified as one significant factor in explaining actual news production-alongside other factors, such as personal values, organisational culture, institutional routines and various systemic constraints (e.g., Preston, 2009; Shoemaker \& Reese, 2014).

The notion of a journalistic role conception is closely associated with other similar concepts, such as journalistic values, journalistic ethics and a professional ethos (Mellado et al., 2017; Plaisance \& Skewes, 2003; Reunanen \& Koljonen, 2016). For instance, prominent journalistic values in Western journalism, such as an orientation towards serving the public good and being autonomous as well as the ethicality, objectivity and topicality of jour- 
nalism (Deuze, 2005, p. 445), are all related to how journalists conceive of their professional role, or what is expected of them. In the end, no clear-cut distinctions can be drawn between these various concepts since all include "ideas about what is good journalism and what is journalism's role in society" (Reunanen \& Koljonen, 2016, p. 2). Here, we prefer the concept of journalistic role to emphasise how journalists perform their professional tasks in social interaction, and how their conception of what is good journalism is shaped by these interactions (see below).

Many recent empirical studies on journalistic roles have taken the form of large-scale surveys, which allows for international comparisons of divergent journalistic cultures (see, e.g., Hanitzsch et al., 2011; Weaver \& Willnat, 2012). Disseminating information, interpreting events and confronting societal powers have been observed to be the most typical roles journalists identify with worldwide (e.g., Carpenter, Boehmer, \& Fico, 2015; Tandoc, Hellmueller, \& Vos, 2013). Nevertheless, notable variations exist between countries concerning the emphasis journalists put on different roles (e.g., Hanitzsch, 2011; Hanusch \& Hanitzsch, 2017).

In the Finnish context, the values of neutrality, objectivity, autonomy and public service characterise how journalists conceive of their professional roles. In a large-scale survey conducted in 2013, Finnish journalists ranked as their most important duties reporting accurately, being an impartial observer, analysing topical issues, telling stories about the world and letting people voice their opinions (Pöyhtäri, Väliverronen, \& Ahva, 2016). Many also emphasised the task of monitoring and scrutinising political leaders and powerful institutions in society. In this regard, Finnish journalists reflect a broader culture of Nordic journalism that corresponds with the political culture of consensual corporatism and with a media system that is characterised by a strong independent press, high degree of professionalism and strong press freedom (Ahva et al., 2017). Finnish journalists tend to see themselves in the service of the general public and the common good rather than as representing a particular interest group or ideology. Thus, even as they increasingly value their role in generating public debate and actively participating in that debate, an ethos of political detachment, independence and neutrality still prevails among Finnish journalists (Reunanen \& Koljonen, 2016). They tend to conceive of their role more in terms of mediating various viewpoints rather than as expressing their own political positions on issues.

\section{A Social-Interactionist View on Journalists' Role Conceptions}

As a method for studying journalists' role conceptions, surveys come with an in-built assumption about role conceptions as explicitly stated tasks and ideals. This is a valid approach in the sense that journalistic roles are partly embedded in the existing institutions of the profession, such as journalistic education, professional associations, media ethical standards and codes of conduct, as well as in media laws and regulations, media organisations and media markets. Indeed, journalistic role conceptions have been observed to be rather constant over time, despite significant changes in the technological means and commercial environments in which journalism operates (Lewis, 2012; O'Sullivan \& Heinonen, 2008). The survey approach, however, tends to have little to say about how, and to what extent, role conceptions operate as cognitive scripts that guide journalists in their actual work. This is problematic because several recent studies have indicated that the actual role performance of journalists often differs from their role conceptions, as stated in surveys, interviews and codes of conduct (Mellado et al., 2017; Tandoc et al., 2013). Moreover, research has long recognised that journalists regularly face conflicting expectations from their surrounding environment and must find ways to negotiate between and combine multiple roles in their work (Hanitzsch \& Vos, 2018; Hellmueller \& Mellado, 2015; Kramp \& Weichert, 2014; Rosten, 1937; Tandoc \& Takahashi, 2014).

In contrast to the survey-based studies on journalists' role conceptions, Hellmueller and Mellado (2015) have recently outlined an alternative approach that focuses on the relational and situated nature of journalistic roles. Rather than understanding journalistic roles as a-contextual tasks and duties, their approach builds on what social psychology identifies as the relational essence of social roles. A role is patterned behaviour that is performed through social interaction and obtains its substance and meaning in relation to other people, whose perceived expectations guide how a person acts within that particular role (Berger \& Luckmann, 1967; Lynch, 2007). Accordingly, a social-interactionist view on journalism emphasises that the practice takes place in particular social situations and journalists make sense of their actions through interactions with reference groups, including sources, audiences and media organisations (Mellado \& Van Dalen, 2014). Journalists perform a particular role in social interaction wherein "they anticipate the consequences of their reporting to others and the social context" (Hellmueller \& Mellado, 2015, p. 6). This perspective adds a fair amount of malleability, negotiability and context-dependence to journalistic roles (Tandoc \& Takahashi, 2014). Journalists may both perceive and enact their roles quite differently according to the topic they are covering, the kind of sources they are engaged with when reporting on the issue and the perceptions they have about the broader societal context. ${ }^{1}$

In line with the social-interactionist approach to roles, the present study focuses on the fluid, relational and situated nature of journalistic roles. We assume that, instead of following clearly defined principles, journal-

\footnotetext{
${ }^{1}$ Discussion on the merits and pitfalls of role theory and its various strands, as they have been developed in the fields of social psychology and sociology, is beyond the scope of this article. For critical overviews, see, for instance, Biddle (1986), Turner (2001), and Lynch (2007).
} 
ists conceive of their roles in relation to the topics they are covering and their perceptions of the broader societal context, and they must creatively interpret them in the face of the often contradictory expectations presented by various reference groups, including sources, audiences and peers. Therefore, journalistic roles are constantly under construction, and journalists must be able to actively choose between various available roles and work out ways to enact them in particular situations. Such selective and creative role performance may concern, for instance, adopting a detached versus an involved stance, choosing between a fact-disseminating role versus an interpretive role requiring analysis and explanation, or serving as a conduit for a variety of societal voices versus being an advocate for a chosen cause (see Tandoc et al., 2013).

Extraordinary conditions that shake existing routines, such as working on a previously unfamiliar topic or in a context of heightened societal tensions surrounding the reported issue, may bring further volatility to journalists' role conceptions. In this respect, the "refugee crisis" presents an interesting case of analysis. First, only a small group of Finnish journalists, mostly working for national media outlets, had significant experience in covering migration issues. Indeed, although a quintessential feature of modern global realities, large-scale migration had nevertheless remained a distant phenomenon for the vast majority of Finns. With the sudden arrival of previously unseen numbers of asylum seekers in reception centres across the country, regional and local reporters quickly needed to address this new topic as part of their daily journalistic routines. Second, reporting on the evolving migration situation brought journalists into contact with a variety of new sources, including asylum officials, asylum seekers and civic groups, which rapidly mobilised around the question of refugees and asylum policy. Journalists hence had to quickly establish professional relationships with, and attitudes towards, reference groups that they had had little previous interaction with. Third, civic mobilisation and the heavily polarised public debate turned asylum into an increasingly delicate topic for journalism. As one sign of the heightened pressure put on journalists, newsrooms and individual reporters frequently received vitriolic feedback on their reporting from various audiences, and they at times became targets of hate speech and even personal threats. All of these aspects potentially had an impact on how Finnish journalists conceived of their professional roles when covering the asylum question during the height of the "refugee crisis".

Thus far, the social-interactionist theorisation on journalistic roles has largely failed to inform empirical studies of journalistic practices (see, however, Tandoc \& Takahashi, 2014). Therefore, aside from generally cited observations about the impact of key reference groups and working contexts on journalists' role conceptions, there is a dearth of knowledge about how journalists actually negotiate their roles when engaged in reporting.
The present study aims to fill in this gap by analysing how journalists narrate their own experiences of being in interaction with key reference groups when covering the refugee situation. In this respect, three reference groups merit particular attention. First, journalists regularly interacted with public officials during the "refugee crisis" because of the heightened public demand for factbased information. Second, asylum seekers themselves were an important reference group as sources for reallife stories. Third, citizen-activists, and particularly antiimmigrant groups, turned into a key reference group for asylum reporters due to their visible online presence and aggressive criticism of refugee journalism. Our purpose is to examine how journalists' role conceptions shift depending on the reference groups they interact with and to focus on their perceptions of the changing political and societal contexts during the "refugee crisis".

\section{Data and Method}

For the purposes of this study, we conducted semistructured interviews with 24 Finnish journalists working in print, television, radio and online news in national (9 interviewees), regional (12) and local (3) news organisations across the country. The interviewees were selected on the basis of their extensive involvement in reporting on asylum-related issues for their news organisations during the period. Some interviewees were identified based on their reporting and recruited directly, while others were contacted through their superiors. The selection included both female (15) and male (9) journalists, with most of them being at mid-career stage, having already acquired several years of work experience as journalists.

The interviews were conducted in between December 2016 and February 2017, and they lasted for approximately 90 minutes. The general themes were as follows: (1) aims and professional ideals in asylum reporting; (2) the performance of the newsroom and the national media in the "refugee crisis"; (3) personal experiences, main sources and challenges in covering the topic; and (4) feedback from audiences and the general opinion climate on immigration. The interviews were transcribed and coded by categorising them according to the main themes of the interviews.

Role conceptions, unlike actual role performances, cannot be directly observed, and therefore, any inferences about the ideas journalists entertain regarding their expected behaviour necessarily rely on what they express in speech or writing. This implies a distinctly interpretive methodology, one aiming at understanding the way people think and feel about themselves in their specific socio-historical circumstances (see Hammersley, 2013, pp. 26-29). While such an analysis can never claim to capture the true conceptions of the studied individuals, it may nevertheless shed important light on journalistic culture, or journalists' shared beliefs and ways of reasoning that influence what they do. As such, role 
conceptions can be studied by asking journalists to explicitly define their (most important or valued) roles and tasks, as is typically done in surveys. Alternatively, they can be inferred from the way journalists talk about their work more generally, alluding to, for instance, their core competences, general motivations, basic ideals and audience perceptions (Donsbach, 2008). While combining both strategies in our interviews, we found that observing the less explicit dimensions of journalists' role discourse proved to be highly rewarding, helping us to discern tensions between various role conceptions and recognise how journalists negotiated between clashing professional norms and values.

When asked directly about their intentions and objectives in reporting on asylum issues, our interviewees tended to allude to a few well-established professional roles among Finnish journalists (see Ahva et al., 2017; Pöyhtäri et al., 2016; Reunanen \& Koljonen, 2016). Establishing and disseminating fact-based information, telling the stories of individual asylum seekers, explaining the asylum issue or mediating public debate as impartial gatekeepers were referred to by many as important tasks, as was the watchdog role of monitoring the conduct of officials and politicians. More nuance-and internal tension-with respect to role conceptions emerged, however, when the interview turned to practical situations and reference groups in asylum reporting. When talking about interviewing an asylum seeker, for instance, the journalists tended to float rather different ideas about what they sought to achieve or how they and their fellow journalists ought to act, compared to when the issue involved covering the operations of officials, investigating anti-immigrant mobilisation or obtaining feedback from readers and viewers. Aside from general tasks and duties, journalists, in other words, seemed to conceive of their roles in relation to other societal groups that they interacted with when reporting on the asylum topic (see Hellmueller \& Mellado, 2015).

Following our interest in the social-interactionist dimension of journalists' role conceptions, the analytical focus here is on both the relational and situational aspects of role conceptions. First, while there are multiple actors and actor groups relevant to a journalist either as a source, fellow worker, superior, authority or audience member, three reference groups-officials, asylum seekers and anti-immigrant groups-specifically stood out during the interviews. Interactions with these three groups appeared to be especially challenging, leading to considerable ambiguity about how they should be treated in asylum reporting. Second, the way our interviewees perceived of these interactions and their professional roles was closely intertwined with their analyses of the broader asylum situation and shifts in the public debate. Contextual considerations, hence, seemed to affect the journalists' negotiation of their professional roles in the public debate. Accordingly, in the following analysis we read the interview text in light of theoretical and research literature on journalistic roles and role con- ceptions, focusing on how the interviewees talked about their work, personal motivations and normative expectations in relation to (1) their interactions with officials, asylum seekers and anti-immigrant groups and (2) the shifting political and societal context of the "refugee crisis".

\section{Analysis}

Journalists' accounts of their interactions with the three reference groups were frequently marked by contradictions about their professional intentions and roles. First, their close interaction with public officials challenged their role conception as independent watchdogs. Second, when interacting with asylum seekers, journalists had to negotiate between perceived expectations of objective dissemination and a more engaged role as an agent of civic education and solidarity towards the plight of refugees. Third, the mobilisation of anti-immigrant groups, including actions against asylum seekers as well as vitriolic criticism, personal threats and online attacks against the news media and individual reporters, unsettled the journalists' conception of themselves as neutral and non-partisan mediators of societal debate. In sum, interactions with these three groups illustrate how Finnish journalists at the time needed to qualify and actively negotiate their preferred role conceptions as neutral and detached watchdogs.

\section{Officials: Collaboration versus Watchdog Role}

The arrival of asylum seekers, mostly from Iraq, Afghanistan, Somalia and Syria, in autumn 2015 was generally experienced by both local and national journalists in Finland as an unprecedented event. As state agencies adopted a series of extraordinary measures, including the rapid opening of new asylum seekers' reception centres in municipalities across the country, editorial offices were trying to keep up to date with the rapidly evolving developments with only limited resources. A constant influx of new and developing information engendered a sense of urgency, uncontrollability and unpredictability in newsrooms. An apparent "crisis mode" of reporting took hold and was characterised by a heavy dependence on officials for information. Without exception, when asked about their most important sources in asylum coverage, our interviewees mentioned public officials, including those at the Finnish Immigration Service, the police, the Ministry of the Interior and the municipal administration.

Given the conditions of a perceived local and national "crisis", a close and mutually beneficial relationship between news journalists and officials was established. Officials provided the journalists with a constant stream of newsworthy facts and sometimes even suggested ideas for new topics to report on. Conversely, the officials could count on journalists to disseminate necessary information to the public. As an illustration of this mutually beneficial relationship, a journalist working for a re- 
gional newspaper in western Finland recounted how he had participated as a representative of his newspaper in a local coordination group set up during the early stages of the "crisis" by administrative agencies, aid organisations and the media for the purpose of sharing information. When asked whether it had been easy to obtain information from officials, he described his relationship with officials in terms of consensual cooperation:

Yes, yes it has been [easy]. Somehow, it feels like these officials also wanted-as openly as they possibly can - to tell everything. So that, the more we have facts out there in the public domain, the easier it is [for people] to understand the situation. That cooperation, I'd say, really has worked quite well in this town. (Journalist 1, regional newspaper, western Finland)

With few exceptions, our interviewees commended the openness of public officials and the access they were given to relevant officials, including the police, asylum officials and the Ministry of the Interior. This experience of openness and willingness to cooperate clearly undermined the journalistic ideal of operating as an independent and critical watchdog. Instead of conceiving themselves as pursuing diverging or even opposing objectives, journalists saw no contradiction of interests between journalism and officials. As Journalist 1 reasoned, they both agreed that openness and the sharing of information and facts served to generate a better public understanding of the situation. In terms of journalistic role conceptions, journalists seemed to adapt to the expectations of the official state apparatus and its interests in quelling potential panic and social unrest (see Christians et al., 2009, p. 217; Hanitzsch \& Vos, 2018, p. 156). Journalism's perceived role as a pillar of social order in cooperation with other arms of the official and unofficial state apparatus overcame its role as a critical watchdog of those arms, and the measure of good journalism was reduced to disseminating reliable (i.e. official) information in an efficient manner (Carpenter et al., 2015).

As a sign of the importance of the watchdog ideal in Finnish journalism (Ahva et al., 2017), however, several interviewees also expressed unease about journalists' close collaboration with officials. They felt that they themselves, or their fellow journalists, had become too dependent on official sources in asylum reporting. Some felt that the problem lay in journalistic routines, which led them to prefer officials rather than alternative sources, while others pointed to practical constraints, namely the poor availability of alternative sources or lack of time to search for them. The importance of maintaining a critical stance towards officials was emphasised especially by journalists working for national news outlets, typically with greater resources to do investigative journalism than the regional media. A journalist working for a national television channel, for instance, criticised her peers for having become too uncritical and easily manipulated as mouthpieces for the police and other officials.
In her view, there were no excuses for journalists not questioning the official versions of events and actively seeking alternative viewpoints:

Pretty much we are at the mercy of officials. Feels like at times they've taken us for a ride. Take police communications-how everything they say has been mediated without being filtered. It's been quite uncritical, I think. I don't understand why. Why haven't we investigated? We have a country full of investigative journalists. (Journalist 2, national television network)

The initial "crisis mode" of asylum reporting subsided in early 2016, in tandem with the rapidly declining number of arriving asylum seekers. With the slowing pace of new developments, the dominance of officials as sources of information decreased and journalists had more time to search for alternative sources as well as to question official views. This, predictably, led to a less harmonious and open relationship with officials. An increasingly critical approach to officials took hold as journalists started to expose, for instance, deficiencies and malpractices in reception centres. Many journalists also began to address questions concerning the observation of human rights in the asylum process. Journalists quickly rediscovered their role as critical watchdogs whose task it was to expose officials' wrongdoings. When asked about what she saw as the most important duty of journalism in asylum reporting, one journalist articulated the watchdog role in unequivocal terms:

Probably one important duty is, of course, to monitor this decision making. To me, it is essential that we can-we must monitor that our justice system operates the way it should operate. That there are no abuses or arbitrariness. Or that those international commitments Finland has signed are implemented, observed. And this has not been the case recently. It is evident. We are-let's say we are only scraping by. So monitoring all this is to me an essential role for us. (Journalist 3, national current affairs magazine)

\section{Asylum Seekers: Advocacy versus Objective Dissemination}

Compared to earlier reporting on migration, asylum seekers became more visible in the Finnish news media during the "refugee crisis" and were interviewed more regularly than in the past. When recounting their encounters with asylum seekers, our interviewees alluded to several professional intentions. First, especially in the early stages of the "crisis", the journalists strived to balance the barrage of official information by adopting the human-interest angle and telling (mostly sympathetic) stories of individual asylum seekers. Many of them saw their task as telling stories about the situation in a way that brought the issues and the people involved closer to the readers, while making asylum seekers and their 
personal circumstances more familiar to local and national audiences. Second, the interviewees intended to bring the otherwise unheard voices of asylum seekers into the public conversation. Hence, covering the asylum seekers' perspective seemed to invoke role conceptions that emphasise the educative and facilitative duties of journalism, focused on raising public awareness and promoting democratic deliberation by bringing a plurality of perspectives into public debate (Christians et al., 2009, pp. 158-159; Hanitzsch \& Vos, 2018, pp. 154-155). When asked about her intentions in asylum reporting, a journalist working for a regional newspaper expressed both these role conceptions:

Perhaps, at least, to bring forward the faces of asylum seekers. To make it evident, in a way, that they are real human beings who live here, amongst us....Perhaps also to give, as many-sided as possible, that space of voice to various people. (Journalist 4, regional newspaper, central Finland)

Third, as the Finnish government started to design and implement restrictive reforms to asylum legislation from late 2015 onwards, and as it put pressure on the Finnish Immigration Agency to process asylum applications more rapidly, many interviewees felt that the system was being turned against asylum seekers. Corresponding with their watchdog role conception, journalists often appeared to identify themselves as defenders of the weak and vulnerable members of society (Christians et al., 2009, pp. 141-142). They, therefore, sought to investigate the cases of individual asylum seekers in order to expose potential flaws and injustices in the asylum system.

The adoption of educative, facilitative and watchdog roles when interacting with asylum seekers implies that journalists experienced a degree of identification with the "cause" of asylum seekers in terms of improving their lot in society. At times, these role conceptions veered towards pro-refugee activism and a political advocacy role, which emphasises the intent of journalists to actively influence audiences and their opinions (Donsbach \& Patterson, 2004; Statham, 2007; Tandoc \& Takahashi, 2014). One journalist, working for a national television network, expressed frustration with the increasingly restrictive asylum policy and the general incapacity of those in opposition to do anything about it. In her view, questioning the legitimacy of the prevailing asylum policy was the goal of critical journalism. This would require a powerful personal story with which people could identify and which would "blow up" the asylum policy debate:

Everyone knows that Finland's asylum policy is stringent. So what would be the story that would blow up this whole thing? It would, once again, require a strong story that people could identify with. That's just how it goes. (Journalist 5, national television network)
Such an open expression of political partisanship regarding the asylum question was, however, the exception rather than the rule. As an indication of the prevalence of Finnish journalists' conception of themselves as apolitical and detached observers (Ahva et al., 2017; Reunanen \& Koljonen, 2016), even those who said they sought to raise awareness, foster empathy and combat xenophobic prejudice by telling the stories of individual asylum seekers typically did not perceive these activities as forms of political advocacy. In addition, many of the interviewees alluded to the principles of neutrality and objectivity in criticism of their peers, who they perceived as having adopted excessively idealistic and naïve views about asylum seekers. In this respect, one frequent criticism of how news journalism covered the asylum issue was that it had suppressed negative facts and views concerning asylum seekers. When asked about how the Finnish media had covered the asylum issue, a regional journalist raised what he perceived as a condescending attitude that prevailed in major national news outlets towards those expressing critical views of asylum seekers. For him, there was a tendency among journalists to discount and condemn all critical opinions as racist:

I think we, the media, Helsingin Sanomat and many other big newspapers as well, were a little bit guilty of being patronising. We somewhat ignored the kind of fears many people had, and prejudices and all that. And certain critical attitudes. To overstate [it] a bit, we gave the message that these people are not benefit seekers, that they are in grave distress [even], that we ought to help them, and that all divergent opining and criticism of this is racism. So keep your mouths shut. (Journalist 6, public service media, regional office)

In the coverage of asylum seekers, the "good" intentions of defending asylum seekers as a marginal and vulnerable group had to be constantly negotiated with respect to the neutral mediator role of journalism, including demands for objectivity, impartiality and neutrality. To achieve neutrality and objectivity, journalists balanced positive stories with more critical perspectives on immigration, including immigrant crime and cultural differences. One journalist, when asked whether she consciously thought about what kinds of perspectives and opinions to make public in her reporting, distanced herself from both the "racists" and "the tolerant" (suvakit)-the latter being a derogatory group label attached by Finnish antiimmigrant online commenters to those they considered to be pro-immigration (i.e., who did not share their views on immigration). Attempting to find a position in the middle, the journalist described her intention to avoid giving "too optimistic an image" of asylum seekers and emphasised the importance of being "realistic" and matter-offact in her reporting. Notably, she was reflective of her shifting role as a journalist in the public debate, alternating between positive and critical representations of immigration, according to the "situation at hand": 
It's absolutely clear that I don't want to give a voice to racists. But I don't deny, I have also intended not to give too optimistic an image of them [asylum seekers]. That I must say. The aim then has been to be realistic and matter-of-fact...I am not the most blue-eyed "tolerant", but I am also not-both according to the situation at hand. (Journalist 7, regional newspaper, central Finland)

\section{Anti-Immigrant Mobilisation: Principled Partisanship versus Impartiality}

The arrival of asylum seekers in large numbers witnessed anti-refugee demonstrations in several municipalities, engendered the organising of far-right street patrols, and even resulted in a few violent attacks against local reception centres. One notable element of the anti-refugee mobilisation was online activism, which included the targeting of mainstream news media and journalists, accusing them of biased reporting in favour of asylum seekers and multiculturalism. Many of our interviewees reported they had been targets of harsh criticism, had been subjected to insults and even threats in online forums and counter-media sites, and had frequently received hate mail concerning their reporting on asylum seekers. While being occasionally criticised for biased reporting is not exceptional, and while this accusation has been regularly heard especially in relation to migration issues, the emergence of an overtly hostile online public had an apparent impact on journalists. Several interviewees acknowledged that they had been upset by the strength of these anti-immigrant reactions and hateful attacks against journalists. Even those interviewees who had not personally received harsh critiques or threats acknowledged being well aware of this public backlash.

There was a notable division among our interviewees concerning their response to such antagonism. Some interviewees had actively countered anti-immigrant arguments in their reports and columns or had attempted to undermine radical right-wing groups by writing critical investigative stories. They tended to perceive antiimmigrant mobilisation as a xenophobic, racist and illiberal reaction, designed to silence liberal voices in society. Because human rights and democratic values appeared to be threatened by this mobilisation effort, remaining "neutral" was not an option-journalists recognised their obligation to defend liberalism and condemn racism and xenophobia. Hence, when speaking in general terms about democratic values, journalists felt entitled to express a principled stance (see Reunanen \& Koljonen, 2016):

My own work has somehow been guided by my values, where, I think, human dignity is universal and human rights issues are important. If we begin to erode them at some end, then we will also further erode them for all. We either have them or we don't. (Journalist 8, joint national newsroom of Finnish regional media)
Adopting a partisan role conception was, hence, one possible response to anti-immigrant mobilisation. For others, however, the perceived obligation to maintain a neutral position guided their reaction. Journalists leaning towards the latter approach attempted to maintain their neutrality by becoming increasingly cautious in their reporting. This involved paying added attention to word choices in reporting so as not to incite controversy or appear to side with a specific group or viewpoint-especially not that of asylum seekers. Reflecting on the impact of audience feedback on his own reporting, one journalist acknowledged that he had intentionally tried to avoid getting a reputation as a partisan reporter, again alluding to the derogatory term "tolerant" that had become increasingly mainstream in public debate:

Perhaps the feedback has had the effect that l've tried to avoid getting too strong a reputation as this kind of a "tolerant" reporter. So I would like to do some major news stories that would also introduce the negative side of things. To somehow demonstrate that I'm not this blue-eyed fella with an illusion that, oh boy, what a nice bunch all these asylum seekers are. Rather, I'm a sensible person who is aware [chuckles] that there are certain problems. (Journalist 9, national television network)

For those striving for a neutral role in the asylum debate, the purpose of reporting was to avoid feeding the goals of the groups with extreme or anti-democratic ideas, who they saw as actively looking for ways to discredit mainstream media as untrustworthy and biased. They felt that any factual mistakes, editorialising or efforts to manipulate readers' emotions in news reporting would be taken advantage of by "the opposite side" to raise moral panic about immigration. Aside from reporting, cautiousness also extended to the journalists' activities in social media, where they consciously toned down personal opining on the issue of asylum seekers.

\section{Discussion}

There is a fair amount of ambiguity and negotiability to journalistic role conceptions. They may be explicitly articulated as ideal types in surveys (Donsbach, 2008), where respondents can rank them in their preferred order, but journalists must eventually interpret their meaning in their actual working practices and in relation to specific news topics. Even when working on a specific beat, journalists entertain several role conceptions, as Tandoc and Takahashi (2014) found when surveying US environmental journalists. Our analysis corroborates their finding. The way Finnish news journalists invoked various journalistic role conceptions when recounting their experiences with asylum reporting suggests that there is no single role that a certain news topic calls for. Journalists alternate rather flexibly from one role conception to another without necessarily demonstrating any great consistency. 
The apparent malleability of journalistic role conceptions gives further import to the social-interactionist approach to journalistic roles. This view emphasises the nature of journalistic roles as relational to reference groups and social contexts (Hellmueller \& Mellado, 2015; Mellado et al., 2017). Interactions with reference groups, perceptions of the broader political context and anticipation of the potential consequences of their reporting are key in informing the journalist about what tasks and objectives one ought to pursue in a particular situation. The analysis presented in this article sheds more light on how this negotiation of professional role conceptions takes place in three ways.

First, the accounts of our interviewees about their interactions with sources and audiences demonstrate how journalists had to develop a certain attitude, and outline a desirable type of conduct, towards those reference groups outside the journalistic community. Asylum officials, asylum seekers and anti-immigrant publics turned out to be particularly central in this regard, typically prompting the interviewees to engage in lengthy reflections about how such groups should be approached, represented and covered in reporting. Whereas interactions with officials tended to strengthen journalists' assumptions of themselves alternatively as cooperative disseminators or as critical watchdogs, asylum seekers inspired journalists to invoke the roles of educators, mediators and even political advocates. The emergence of anti-immigrant mobilisation as a vocal adversary of mainstream journalists, in turn, encouraged some to embrace a partisan position in defence of liberal values, while others refused to get involved in a public confrontation and instead opted for guarding their role conception as neutral observers. Second, identification with these alternative role conceptions was seldom straightforward or entirely consistent, indicating how our interviewees often struggled to position themselves with regard to the three reference groups. This apparent unease may have resulted from the unusual situation in which the reporting took place. Indeed, extraordinary events such as the "refugee crisis" may bring reporters into contact with new reference groups, or change the usual dynamics with old ones. This can unsettle established role conceptions and reactivate the "boundary work" of journalists as they seek to define themselves in reference to others (see Lynch, 2007). Conversely, in normal times journalistic relations with reference groups may be highly routinised and are much more likely to reaffirm the journalists' existing role conceptions.

Third, the way our interviewees recounted the "refugee crisis", and its shifting political and societal repercussions, demonstrates how contextual considerations affect the interpretation of journalistic roles. While neutrality, objectivity and apolitical detachment continue to be valued ideals among Finnish journalists (Ahva et al., 2017; Reunanen \& Koljonen, 2016), reporters must interpret what they mean with respect to concrete issues. Moreover, even as they tend to assume that neu- trality means occupying the "middle ground" in disputes (Campbell, 1987; Durham, 1998), journalists must first establish where this middle ground exists in a given debate and at a given point in time. In the asylum debate, the rise of anti-immigrant voices and their rhetorical strategy of constructing an internal foe out of "the tolerant" (i.e., those who did not agree with their views on immigration) seemed to have the effect of moving the middle ground for many of our interviewees: it came to exist between "the tolerant" and "the racists". For those not willing to embrace an advocacy-oriented position in the public debate as a defender of the weak and vulnerable outsiders, guarding a conception of oneself as an impartial observer meant that the journalist had to shy away from (openly) empathising with the asylum seekers' cause and from standing out as actively opposing the anti-immigrant views. The defence of democracy and human rights could be negotiated within this neutral position insofar as they were conceived of as universal-and hence, apolitical-values and not associated with the interests of any participants in the societal conflict.

\section{Conclusion}

This study has focused on the influence external groups have on journalistic role conceptions. Our intention, however, has not been to downplay the importance of education, the working environment and other contexts of professional socialisation for the development of journalistic role conceptions. Factors internal to the journalistic profession, including media organisations and the broader institutional culture, are undoubtedly vital in moulding the perceived societal expectations attached to journalism as a practice (e.g., Ahva et al., 2017; Preston, 2009). Nevertheless, the social-interactionist approach provides an important addition to the study of journalistic roles by reminding us about the rootedness of journalistic roles in social relations and politicohistorical contexts (Hellmueller \& Mellado, 2015).

The recent social and political conflicts concerning refugees are indicative of the tensions European societies are struggling with in adapting to large-scale migration, both voluntary and forced, which is part and parcel of contemporary global capitalism (Žižek, 2016). Concurrently, the move towards increasingly multicultural societies introduces various new challenges to journalism and places new demands on it, including greater knowledge of and sensitivity towards other cultures, the representation of minorities and the diversity of covered viewpoints as well as finding solutions to societal problems, such as intercultural conflicts and racism (e.g., Deuze, 2005; Eide \& Nikunen, 2011). As indicated by our interviewees' experiences in the "refugee crisis", the increasing connectedness of localities to transnational processes also brings journalists into contact with individuals and groups they previously had little interaction with. All of these changes will potentially destabilise traditional con- 
ceptions of what it means to be a journalist and call for their active negotiation.

Far from being an insulated field with autonomous rules and operational norms, journalism is being carried out in continuous interaction with other societal groups, and this interaction shapes the journalistic profession, including journalists' conceptions of their tasks and duties. Hence, despite the relevance of professional socialisation as the fundamental basis of journalistic role conceptions, this study has sought to demonstrate how dealing with contradictory expectations and contextual considerations in concrete situations, especially in shifting political and societal contexts, are necessarily part of journalists' sense-making and negotiation process concerning their roles. Further studies should aim at further analysing, and theorising about, the interplay between internal and external influences on journalistic role conceptions.

\section{Acknowledgments}

The authors appreciate the feedback given on earlier versions of this manuscript by Kaarina Nikunen and Mervi Pantti, as well as the reviewers and editors. Research was supported by the Helsingin Sanomat Foundation. Our special gratitude goes to the journalists who participated in the interviews.

\section{Conflict of Interests}

The authors declare no conflict of interests.

\section{References}

Ahva, L., van Dalen, A., Hovden, J. F., Kolbeins, G. H., Nilsson, M. L., Skovsgaard, M., \& Väliverronen J. (2017). A welfare state of mind? Nordic journalists' conception of their role and autonomy in international context. Journalism Studies, 18(5), 595-613.

Berger, P. L., \& Luckmann, T. (1967). The social construction of reality. New York, NY: Doubleday.

Berglez, P. (2013). Global journalism: Theory and practice. New York, NY: Peter Lang.

Biddle, B. J. (1986). Recent developments in role theory. Annual Review of Sociology, 12, 67-92.

Campbell, R. (1987). Securing the middle ground: Reporter formulas in 60 minutes. Critical Studies in Mass Communication, 4(4), 325-350.

Carpenter, S., Boehmer, J., \& Fico, F. (2015). The measurement of journalistic role enactments: A study of organizational constraints and support in for-profit and nonprofit journalism. Journalism \& Mass Communication Quarterly. doi:10.1177/ 1077699015607335

Christians, C. G., Glasser, T. L., McQuail, D., Nordenstreng, K., \& White, R. A. (2009). Normative theories of the media: Journalism in democratic societies. Urbana and Chicago, IL: University of Illinois Press.
Deuze, M. (2005). What is journalism? Professional identity and ideology of journalists reconsidered. Journalism, 6(4), 442-464.

Donsbach, W. (2008). Journalists' role perceptions. In W. Donsbach (Ed.), The international encyclopedia of communication (pp. 2605-2610). Malden, MA: Wiley-Blackwell.

Donsbach, W., \& Patterson, T. (2004). Political news journalists: Partisanship, professionalism, and political roles in five countries. In F. Esser \& B. Pfetsch (Eds.), Comparing political communication: Theories, cases and challenges (pp. 251-270). Cambridge: Cambridge University Press.

Durham, M. G. (1998). On the relevance of standpoint epistemology to the practice of journalism: The case for "strong objectivity". Communication Theory, 8(2), 117-140.

Eide, E., \& Nikunen, K. (Eds.). (2011). Media in motion. Cultural complexity and migration in the Nordic region. Farnham: Ashgate.

Eurostat. (2016, March 4). Record number of over 1.2 million first time asylum seekers registered in 2015 [News release]. Retrieved from http://ec.europa.eu/ eurostat/documents/2995521/7203832/3-04032016 -AP-EN.pdf

Gans, H. J. (1979). Deciding what's news. New York, NY: Vintage.

Greussing, E., \& Boomgaarden, H. G. (2017). Shifting the refugee narrative? An automated frame analysis of Europe's 2015 refugee crisis. Journal of Ethnic and Migration Studies, 43(11), 1749-1774.

Hammersley, M. (2013). What is qualitative research? London: Bloomsbury.

Hanitzsch, T. (2011). Populist disseminators, detached watchdogs, critical change agents and opportunist facilitators: Professional milieus, the journalistic field and autonomy in 18 Countries. International Communication Gazette, 73(6), 477-494.

Hanitzsch, T., Hanusch, F., Mellado, C., Anikina, M., Berganza, R., Cangoz, I., . . . Yuen, E. K. W. (2011). Mapping journalism cultures across nations: A comparative study of 18 Countries. Journalism Studies, 12(3), 273-293.

Hanitzsch, T., \& Vos, T. P. (2018). Journalism beyond democracy: A new look into journalistic roles in political and everyday life. Journalism, 19(2), 146-164.

Hanusch, F., \& Hanitzsch, T. (2017). Introduction: Comparing journalistic cultures across nations. Journalism Studies, 18(5), 525-535.

Harrison, A. C. (2016). Mediations of "the refugee crisis": The (ir)reconciliation of ideological contradictions in Fortress Europe. Networking Knowledge, 9(4). Retrieved from https://ojs.meccsa.org.uk/ index.php/netknow/article/view/445/267

Hellmueller, L., \& Mellado, C. (2015). Professional roles and news construction: A media sociology conceptualization of journalists' role conception and performance. Communication \& Society, 28(3), 1-11. 
Holmes, S. M., \& Castañeda, H. (2016). Representing the "European refugee crisis" in Germany and beyond: Deservingness and difference, life and death. American Ethnologist, 43(1), 12-24.

Kramp, L., \& Weichert, S. (2014). Covering the world in despair: A survey of German crisis reporters. Journal of War \& Culture Studies, 7(1), 18-35.

Lewis, S. C. (2012). The tension between professional control and open participation: Journalism and its boundaries. Information, Communication \& Society, 15(6), 836-866.

Lynch, K. D. (2007). Modeling role enactment: Linking role theory and social cognition. Journal for the Theory of Social Behaviour, 37(4), 379-399.

Mellado, C., Hellmueller, L., \& Donsbach, W. (2017). Journalistic role performance: Concepts, contexts, and methods. London: Routledge.

Mellado, C., \& Van Dalen, A. (2014). Between rhetoric and practice: Explaining the gap between role conception and performance in journalism. Journalism Studies, 15(6), 859-878.

Ojala, M. (2011). Mediating global imaginary: Obama's "address to the Muslim world" in the Western European press. Journalism Studies, 12(5), 673-688.

O’Sullivan. J., \& Heinonen, A. (2008). Old values, new media: Journalism role perceptions in a changing world. Journalism Practice, 2(3), 357-371.

Plaisance, P. L., \& Skewes, E. A. (2003). Personal and professional dimensions of news work: Exploring the link between journalists' values and roles. Journalism \& Mass Communication Quarterly, 80(4), 833-848.

Pöyhtäri, R., Väliverronen, J., \& Ahva, L. (2016). Suomalaisen journalistin itseymmärrys muutosten keskellä [The self-image of the Finnish journalist in times of change]. Media \& Viestintä, 39(1), 32-54.

Preston, P. (2009). Making the news: Journalism and news cultures in Europe. New York, NY: Routledge.

Reunanen, E., \& Koljonen, K. (2016). Not partisans, but participants: The quantity and quality of journalistic interventionism in Finnish journalists' professional ethos. Journalism Studies. doi:10.1080/ 1461670X.2016.1204940

Rosten, L. C. (1937). President Roosevelt and the Washington correspondents. Public Opinion Quarterly, 1(1), 36-52.

Shoemaker, P. J., \& Reese, S. D. (2014). Mediating the message in the 21st century. London: Routledge.

Siebert, F. S., Peterson, T., \& Schramm, W. (1956). Four theories of the press. Urbana and Chicago, IL: University of Illinois Press.

Statham, P. (2007). Journalists as commentators on European politics: Educators, partisans or ideologues? European Journal of Communication, 22(4), 461-477.

Tandoc, E. C., Jr., Hellmueller, L., \& Vos, T. P. (2013). Mind the gap: Between journalistic role conception and role enactment. Journalism Practice, 7(5), 539-554.

Tandoc, E. C., Jr., \& Takahashi, B. (2014). Playing a crusader role or just playing by the rules? Role conceptions and role inconsistencies among environmental journalists. Journalism, 15(7), 889-907.

Tuchman, G. (1978). Making news. New York, NY: Free Press.

Turner, R. H. (2001). Role theory. In J. H. Turner (Ed.), Handbook of sociological theory (pp. 233-254). New York, NY: Springer.

Vertovec, S., \& Wessendorf, S. (Eds.). (2010). The multiculturalism backlash. European discourses, policies and practices. London: Routledge.

Weaver, D. H., \& Willnat, L. (Eds.). (2012). The global journalist in the 21st century. London: Routledge.

Žižek, S. (2016). Against the double blackmail. London: Allen Lane.

\section{About the Authors}

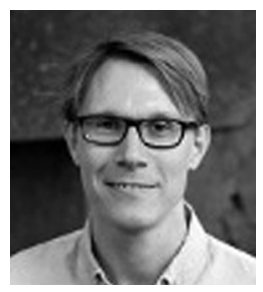

Markus Ojala is a University Lecturer at the Department of Social Research, University of Helsinki, Finland. His research interests lie at the intersection of international political economy, the public sphere theory, and journalism studies. His publications include articles in International Journal of Communication, Journalism, Journalism Studies, and Media, Culture \& Society.

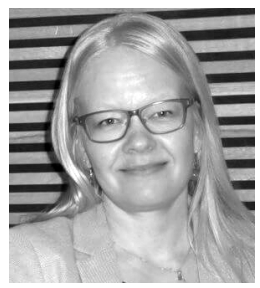

Reeta Pöyhtäri (PhD) works as a Post-Doctoral researcher at the Research Centre for Journalism, Media and Communication COMET, University of Tampere, Finland. Her research interests are related to public discourse and rights-based questions in the digital media environment, including freedom of expression, hate speech and cyber-violence, migration in the media, safety of journalists, as well as journalistic ethics and practices. 